\title{
Contradictory genetic make-up of Dutch harbour porpoises: response to van der Plas-
}

\section{Duivesteijn et al.}

Anna M. Kopps \& Per J. Palsbøll

Affiliation:

Groningen Institute for Evolutionary Life Sciences, University of Groningen, Linnaeusborg, 9747 AG Groningen, The Netherlands

Email: anna.kopps@gmx.com

The assessment of the status of endangered species or populations typically draw generously on the plethora of population genetic software available to detect population genetic structuring. However, despite the many available analytical approaches, population genetic inference methods [of neutral genetic variation] essentially capture three basic processes; migration, random genetic drift and mutation. Consequently, different analytical approaches essentially capture the same basic process, and should yield consistent results.

Recently, van der Plas-Duivesteijn et al. (2015) presented a genetic assessment of harbour porpoises, Phocoena phocoena, along the Dutch coast, which concluded that all analysed Dutch harbor porpoises are part of the same interbreeding population while also concluding that Dutch harbour porpoises were inbred. These two main conclusions are contradictory as the same individuals cannot be both in- and outbred unless the population is very small, which is not supported by the data. Here we carefully review the analyses conducted by van der Plas-Duivesteijn et al. (2015) and revise the conclusions. 
Van der Plas-Duivesteijn et al. (2015) concluded that Dutch harbour porpoises are inbred because four of the nine microsatellite loci showed statistically significantly elevated levels of homozygosity. There are multiple possible causes of elevated homozygosity, such as (i) selection, (ii) technical aspects (e.g., null-alleles or scoring errors) and (ii) non-random mating.

Selection is unlikely to affect four of nine random microsatellite loci and would necessitate unusually high selection coefficients to yield a detectable effect.

The statistical tests employed to detect the presence of null-alleles and non-random mating are more or less identical and based upon the probability of the observed homozygosity under the null-hypothesis of random mating making it unnecessary to conduct separate tests. Before making inferences about non-random mating, the contribution from technical aspects, such as null-alleles and/or scoring errors, must be minimized and the error rate included in the results. Should the elevated levels of homozygosity persist after minimizing the error rate, then it is reasonable to conclude that the samples do not originate from a single, randomly mating population. Several different biological and sampling processes can lead to apparent non-random mating, such as (i) assortative mating, (ii) sampling scheme and (ii) the pooling of samples from more than one populations.

A non-random sampling scheme can lead to non-independent sampling of closely related individuals, such as mother-offspring pairs. However (apart from the inclusion of a mother and her foetus in the analyses), such non-random sampling is unlikely to apply to stranded harbour porpoises (Wright et al. 2013).

The Wahlund effect (Wahlund 1928) refers to elevated levels of homozygosity due to subpopulation structure, and is expected if harbor porpoises off the Dutch coast originate 
from multiple north-eastern Atlantic harbour porpoise "populations" as suggested by Andersen et al. (2001).

The conclusion that Dutch harbour porpoises are outbred (van der Plas-Duivesteijn et al. 2015) is based upon the failure to reject genetic homogeneity in their sample, which is an incorrect interpretation of the failure to reject the null-hypothesis. Any inference concerning population structure requires an a priori definition of what constitutes a population. Failure to reject genetic homogeneity may simply be due to low statistical power and hence the effect size (i.e., the degree of population structure) as well as the uncertainty of the estimate of population structure must be taken into consideration, rather than focusing on the probability of the null-hypothesis (Waples and Gaggiotti 2006; Palsbøll et al. 2007). An illustrative example is the assessment of the population structure assumed in Baltic harbour porpoises based on mitochondrial DNA because the null-hypothesis of homogeneity was rejected (Wang and Berggren 1997). Palmé and co-workers (2008) later demonstrated that the observed genetic divergence was plausible under migration rates supporting both isolation and a randomly mating Baltic-Belt-Kattegat-Skagerrak population.

If the presence of spatial structure in mitochondrial DNA frequencies and the absence of structure in microsatellites in Dutch harbour porpoises claimed by van der PlasDuivesteijn et al. (2015) withstand more rigorous testing, these results could indicate sex differences in dispersal and philopatry. Therefore, the contradictory results of two genetic marker types do not necessarily imply that one result is erroneous (van der Plas-Duivesteijn et al. 2015), on the contrary, such an outcome provides additional insights into the species' life history, as has been shown for numerous species including cetaceans (e.g., Palsbøll et al. 1995; Kopps et al. 2014). 
In conclusion, the data presented by van der Plas-Duivesteijn et al. (2015) need additional analyses and a consistent interpretation before solid conclusions can be drawn to guide the conservation of Dutch harbor porpoises. Contrary to more basic academic endeavours, applied conservation biology research has direct impact on societal (mis)investments. Accordingly it is crucial that the basis is solid.

\section{Acknowledgements}

AMK was supported by a fellowship for prospective researchers from the Swiss National Science Foundation. We would like to thank one anonymous reviewer for helpful comments.

\section{References}

Andersen, L., Ruzzante, D., Walton, M., Berggren, P., Bjørge, A., Lockyer, C., 2001.

Conservation genetics of harbour porpoises, Phocoena phocoena, in eastern and central North Atlantic. Conservation Genetics 2: 309-324. DOI:

10.1023/A:1012534212853

Kopps, A.M., Ackermann, C.Y., Sherwin, W.B., Allen, S.J., Bejder, L., Krützen, M., 2014. Cultural transmission of tool use combined with habitat specialisations leads to finescale genetic structure in bottlenose dolphins Proceedings of the Royal Society B: Biological Sciences 281: 20133245. DOI: 10.1098/rspb.2013.3245

Palmé, A., Laikre, L. , Utter, F., Ryman, N., 2008. Conservation genetics without knowing what to conserve: the case of the Baltic harbour porpoise Phocoena phocoena. Oryx 42: 305-308. DOI:10.1017/S0030605308006960 
Palsbøll, P.J., Bérubé, M., Allendorf, F.W., 2007. Identification of management units using population genetic data. Trends in Ecology \& Evolution 22: 11-16. DOI: 10.1016/j.tree.2006.09.003

Palsbøll, P.J., Clapham, P.J., Mattila, D.K., Larsen, F., Sears R., Siegismund, H.R., Sigurjonsson, J., Vasquez, O., 1995. Distribution of mtDNA haplotypes in North Atlantic humpback whales: the influence of behaviour on population structure. Marine Ecology Progress Series 116.

van der Plas-Duivesteijn, S.J., Smit, F.J.L., van Alphen, J.J.M., Kraaijeveld, K., 2015. Harbor porpoise Phocoena phocoena strandings on the Dutch coast: No genetic structure, but evidence of inbreeding. Journal of Sea Research 97: 24-27. DOI: 10.1016/j.seares.2014.12.009

Wahlund, S., 1928. Zusammensetzung von Population und Korrelationserscheinung vom Standpunkt der Vererbungslehre aus betrachtet. Hereditas 11: 65-106. DOI: 10.1111/j.1601-5223.1928.tb02483.x

Wang, J.Y., Berggren, P., 1997. Mitochondrial DNA analysis of harbour porpoises (Phocoena phocoena) in the Baltic Sea, the Kattegat-Skagerrak Seas and off the west coast of Norway. Marine Biology 127: 531-537. DOI: 10.1007/s002270050042

Waples, R.S., Gaggiotti, O., 2006. What is a population? An empirical evaluation of some genetic methods for identifying the number of gene pools and their degree of connectivity. Molecular Ecology 15: 1419-1439. DOI: 10.1111/j.1365$294 X .2006 .02890 . x$ 
Wright, A.J., Maar, M., Mohn, C., Nabe-Nielsen, J., Siebert, U., Jensen, L.F., Baagøe, H.J., Teilmann, J., 2013. Possible Causes of a Harbour Porpoise Mass Stranding in Danish Waters in 2005. PLoS ONE 8: e55553. DOI: 10.1371/journal.pone.0055553 